\title{
Yenilenebilen ve Yenilenemeyen Enerjinin İktisadi Büyüme Üzerindeki Etkisi: 28 OECD Ülkesi Üzerine Ampirik Bir Çalışma ${ }^{1}$
}

\author{
Ramazan Kılıç² \\ Volkan Aslan ${ }^{3}$
}

Yenilenebilen ve Yenilenemeyen Enerjinin iktisadi Büyüme Üzerindeki Etkisi: 28 OECD Ülkesi Üzerine Ampirik Bir Çalışma

\section{Öz}

$\mathrm{Bu}$ çalışma yenilenebilir ve yenilenemeyen enerji tüketimi ile iktisadi büyüme ilişkisini araştırmaktır. Bu amaçla 1990-2013 dönemi yıllık verileri ile 28 OECD ülkesi üzerine ampirik bir çalışma yapılmıştır. Uygulamada, Johansen Fisher ve Pedroni eş bütünleşme ve Granger nedensellik testleri kullanılmıştır. Pedroni FMOLS yöntemi ile değişkenler arasında tespit edilen uzun dönem eş bütünleşme ilişkisinin katsayıları araştırılmıştır. Elde edilen bulgulardan, değişkenler arasında uzun dönemli bir eş bütünleşmenin olduğu sonucuna varılmıştır. FMOLS testi ile uzun dönemli katsayıları elde edilen OECD ülkelerinden bazılarının yenilenemeyen enerjiden olumsuz etkilendikleri görülmüştür. Yine bu iki testten elde edilen ülke katsayılarına göre yenilenebilir enerji kullanımının, 28 OECD ülkesinin tamamının iktisadi büyümesine katkı sağladığı tespit edilmiştir.

Anahtar Kelimeler: Yenilenebilir Enerji, İktisadi Büyüme, Panel Veri Analizi.

\author{
Influence of Renewable and Non-Renewable Energy on \\ Economic Growth: An Empirical Study on 28 OECD \\ Countries
}

Abstract

This study investigates the relationship between economic growth and renewable and non-renewable energy consumption. An empirical study has been carried out for 28 OECD countries by using annual data between 1990-2013. We used Pedroni and Fisher-Johansen cointegration and Granger causality tests. We also employed Pedroni FMOLS method to investigate coefficients of previously identified long term co-integration relationship. According to the results, we found long term co-integration relationship among the variables. From FMOLS test results, it is found that some OECD countries negatively affected from nonrenewable energy consumption. It is also ascertained from FMOLS results that, renewable energy consumption contributes to economic growth of 28 OECD countries.

Keywords: Renewable Energy, Economic Growth, Panel Data Analysis.

\section{Giriş}

Enerji, insanların hayatlarını sürdürebilmesinde ihtiyaç duydukları önemli bir gereksinim olarak tarihteki yerini alırken, üretim sürecinde de vazgeçilmez bir girdi olmuştur. Özellikle sanayi devriminden günümüze kadar geçen süreçte, enerji ihtiyacı, toplumların refah düzeylerinin gelişmesiyle hızlı bir şekilde artmıştır. Günümüzde modern sanayilerin üretimi, çok büyük oranda insan gücü dışındaki kaynaklardan sağlanan enerjiye dayanmaktadır. Bugün enerji talebi, tarihin hiçbir döneminde rastlanmayacak seviyeye gelmiştir.

Enerji kaynaklarının sınıflandırılması, enerjinin elde ediliş şekillerine göre birincil ve ikincil enerji kaynakları olarak yapılmaktadır. Birincil enerji kaynakları, kömür, ham petrol, doğalgaz, biyokütle, güneş, rüzgar, su gücü gibi doğada bulundukları şekilde, doğrudan kullanılabilen kaynaklardır. Bu kaynaklar da yenilenemeyen (fosil enerji) ve yenilenebilir kaynaklar olarak

\footnotetext{
${ }^{1}$ Bu çalışma Dumlupınar Üniversitesi Sosyal Bilimler Enstitüsü İktisat Anabilim Dalı’nda Prof. Dr. Ramazan Kılıç danışmanlığında Volkan Aslan tarafından "Yenilenebilen ve Yenilenemeyen Enerjinin İktisadi Büyüme Üzerindeki Etkisi: 28 OECD Ülkesi Üzerine Ampirik Bir Çalışma" ismiyle tamamlanarak 20.10.2015 tarihinde savunulan yüksek lisans tezinden türetilmiştir.

${ }^{2}$ Prof. Dr., Dumlupınar Üniversitesi, IỉBF, İktisat Bölümü. ramazan.kilic@dpu.edu.tr

${ }^{3}$ Arş. Gör., Dumlupınar Üniversitesi, iỉBF, iktisat Bölümü. volkan.aslan@dpu.edu.tr
} 
ikiye ayrılmaktadır. Yenilenemeyen ya da yeraltı enerji kaynakları olarak da adlandırılan fosil enerji kaynaklarını kömür, petrol, doğal gaz oluştururken, yenilenebilir enerji kaynaklarını ise güneş enerjisi, hidrolik enerji (su gücü), jeotermal enerji, rüzgar enerjisi, biyokütle ve atık enerjisi oluşturmaktadır.

Gelişen teknolojiyle fosil ve nükleer enerji kullanımındaki artış beraberinde çeşitli çevre sorunlarını da ortaya çıkarmıştır. Bunların başında küresel ısınma, iklim değişikliği, atmosfer kirliliği ve sera etkisi gibi değişik isimler altında hep aynı olumsuzluğu teşkil eden sorunlar yer almaktadır. Bütün bu sorunlara karşın son yıllarda dünyada artan çevre bilincinin etkisiyle, daha temiz, sürdürülebilir bir çevre anlayışı doğmuş ve çevresel sorunların çözümü için ülkelerin yenilenebilir enerji politikalarında önemli derecede değişmeler olmuştur. Yenilenebilir enerjinin, diğer enerji türlerine göre, karbondioksit emisyonlarını azaltarak çevreyi korumaları dışında daha birçok avantajı bulunmaktadır. Yenilenebilir enerji kaynaklarının en büyük özellikleri; temiz ve zararsız enerji olmaları, yerli kaynaklar oldukları için enerjide dışa bağımlılığın azalmasına ve istihdamın artmasına katkıda bulunmaları ve dünya kamuoyundan güçlü destek almalarıdır. Dolaysıyla yenilenebilir enerji kullanımı, sürdürülebilir iktisadi büyüme ve gelişmeye katkı sağlamaktadır. Bu yüzden ülkeler, kademeli olarak fosil kaynakların tüketimini azaltıp yenilenebilir enerji tüketimini arttırmayı planlamaktadır. Bu noktadan hareketle bu çalışmanın amacı, yenilenebilir ve yenilenemeyen enerji tüketimi ile iktisadi büyüme ilişkisini araştırmaktır.

\section{Teorik Çerçeve}

Iktisadi büyüme bir ülkede yıldan yıla üretimde meydana gelen reel artış olarak tanımlandığına göre üretime katılan çıktı miktarındaki artış ne kadar büyükse ekonomik büyümenin de buna oranla o kadar büyük olması beklenir. Bir ekonomide iktisadi büyümenin belirleyicileri; iş gücü ve nüfus artışı, sermaye birikimi, doğal kaynaklardaki artışlar ve teknolojik gelişmeler olarak kabul edilmektedir. Enerjinin bir üretim girdisi olarak önemi ise 1970'li yıllardaki enerji krizlerinden sonra anlaşılmıştır. Özellikle gelişmiş ülkeler üzerinde olumsuz etkisi daha çok görülen bu kriz döneminden sonra enerji ve ekonomik büyüme kavramları daha çok birlikte anılır hale gelmişlerdir.

Hamilton (1983), Burbridge ve Harisson (1984) gibi neo-klasik iktisatçılara göre enerji, ekonomide büyük bir rol oynayabilmektedir. Sanayide kullanılan enerji miktarı arttıkça üretim miktarının ve dolayısıyla hasılanın artacağı varsayıldığında, tek sektörlü neo-klasik üretim teknolojisi çerçevesinde sermaye (K), işgücü (L) ve enerji $(E)$ ayrı girdiler olarak tanımlanır. Böylece üretim fonksiyonu aşağıdaki gibi yazılabilir (Ghali ve Sakka, 2004:228):

$Q=f(K, L, E)$

Bu çerçevede, iktisadi büyüme söz konusu olduğunda yukarıdaki üretim fonksiyonu içinde yer alan üç temel üretim faktörü arasındaki ilişki de önem kazanmaktadır. Enerji ile ekonomik büyüme arasındaki pozitif yönlü bir ilişkide, enerji tüketimini azaltıcı yönde uygulamalar ekonomik büyümeyi olumsuz etkileyebilecektir (Stern ve Cleveland, 2004: 20).

Fosil enerji tüketimindeki hızlı artışla CO2 salınımının tehlikeli boyutlara ulaştığı son yıllarda bu konuda yapılmış olan çalışmalar hız kazanmıştır. Yapılan çalışmalarda enerji tüketimi ve büyümenin nedensellik yönü dört farklı hipotezle sınanmaktadır. Bunlar;

- Geribildirim hipotezi $(\mathrm{ET} \leftarrow \rightarrow \mathrm{GSY}$ iH); nedensellik yönünün enerji tüketimi ve büyüme arasında çift yönlü olduğunu kabul eder. 
- Büyüme hipotezi (ET $\rightarrow$ GSYiH); nedensellik yönünün enerji tüketiminden büyümeye doğru olduğunu kabul eder.

- Doğal kaynakların korunma hipotezi (GSYiH $\rightarrow E T)$; nedensellik yönünün ekonomik büyümeden enerji tüketimine doğru olduğunu kabul eder.

- Tarafsızlık hipotezi (GSYiH----ET); nedensellik yönünün iki değişken arasında olmadığını yani birbirinden etkilenmediğini kabul eder.

Çalışmanın ilerleyen bölümlerinde bu dört hipotezin varlığı Granger nedensellik testi ile sınanacaktır.

\section{Ampirik Literatür Taraması}

Literatürde enerji tüketimi ile iktisadi büyüme ilişkisini konu edinen birçok çalışma yer almaktadır. Özellikle son on yılda enerji üzerine yapılan çalışmalara bakıldığında, yenilenebilir enerji ve iktisadi büyüme ilişkisinin daha fazla incelendiği görülmektedir.

Bu çalışmada yukarıda verilen dört hipoteze göre enerji tüketimi ve büyüme arasındaki nedensellik ve eş bütünleşme ilişkisi, ampirik literatür taraması altında incelenmiştir. Enerji tüketimi ile ekonomik büyüme arasındaki nedensellik ilişkisine yönelik ilk çalışma Kraft ve Kraft (1978) tarafından ABD üzerine 1947-1974 dönemi verileri kullanılarak yapılmıştır. Çalışma sonucunda enerji tüketiminden GSYiH'ye doğru tek yönlü bir nedensellik bulunmuştur. Bu çalışmadan sonra enerji ve ekonomik büyüme ilişkisini inceleyen araştırmaların sayısı giderek artmaya başlamıştır.

Literatürde son yıllarda yapılan örneklem sayısı yüksek eş bütünleşme ve nedenselliğin araştırıldığı çalışmalara bakıldığında; 1971-2001 yılları arasında 19 Afrika ülkesi üzerine yaptığı çalışmada, Wolde-Rufael (2005), bazı Afrika ülkelerinde GSYiH'den enerji tüketimine, bazılarında enerji tüketiminden GSYï'ye doğru tek yönlü bir nedensellik ilişkisi bulmuştur. Aynı çalışmada elde edilen bulgulara göre bazı ülkeler arasında enerji tüketimi ve GSYiH arasında çift yönlü bir ilişkinin olduğu görülmüştür.

Lee(2006)'nin 1960-2001 yılını kapsayan 11 gelişmiş ülkeyi dahil ettiği çalışmasında, Grenger nedensellik testi sonuçlarına göre büyüme ve enerji tüketimi ilişkisi, ülkelere göre farklı farklı sonuçlar vermiştir.

Mehrara (2007), 1971-2002 yılları verilerini kullanarak petrol ihraç eden 11 ülkeyi ele aldığı çalışmasında, panel eş bütünleşme yöntemi kullanarak GSYiH'den enerji tüketimine doğru tek yönlü bir nedensellik ilişkisi tespit etmiştir.

Lee ve Chang (2008)'in çalışmalarında 1971-2002 döneminde 16 Asya ülkesi için enerji tüketimi ile GSYiH arasındaki nedensellik ilişkisi ve uzun dönem ilişkisi analiz edilmiştir. Analiz sonuçlarına göre, GSYiH ile enerji tüketimi arasında uzun dönemde pozitif bir ilişkinin desteklendiği ve enerji tüketiminden ekonomik büyümeye tek yönlü bir nedensellik tespit edilmiştir.

Narayan ve Smyt (2008)'in, 1972-2002 dönemini kapsayan, panel eş bütünleşme ve Granger nedensellik testleri ile G7 ülkelerini analiz ettiği çalışmasında, enerji tüketiminden GSYiH'ye tek yönlü bir nedensellik ilişkisi ortaya çıkmıştır.

Apergis ve Payne (2009a), 6 ülke üzerine yaptığı 1980-2004 dönemini kapsayan çalışmalarında, panel eş bütünleşme yöntemi ve hata düzeltme modeli ile uzun dönemde enerji tüketiminden GSYiH'ye tek yönlü bir nedensellik ilişkisi belirlemişlerdir. 
Apergis ve Payne (2009b)'in 6 ülke üzerine yaptığı 1971-2004 dönemini kapsayan kısa dönemli başka bir çalışmalarında ise enerji tüketimi ve büyüme arasında çift yönlü nedensellik ilişkisi görülmüştür.

Romano ve Scandurra (2013) çalışmalarında 1980-2007 dönemini kapsayan yıllık veriler kullanılarak enerji tüketimi ile reel GSYH ilişkisi İtalya bölgelerinde incelenmiştir. Panel eş bütünleşme ve panel vektör hata düzeltme modelleri iki değişken arasındaki nedenselliğin dinamik yönlerini açıklamak için kullanılmıştır. Analiz sonuçlarına göre uzun dönemli nedensellik tespit edilmekle birlikte hem kısa hem uzun dönemde çift yönlü nedenselliğin varlığına ulaşılmıştır.

Acaravcı ve Öztürk (2010)'ün 15 geçiş ekonomisini 1990 ve 2006 yılları arasındaki zaman dilimi için inceledikleri fakat kullandıkları veri seti eş bütünleşik olmadığı için nedensellik analizi yapmayarak, söz konusu ülkelerde ekonomik büyüme ve enerji politikalarının birbirini etkilemeyeceği sonucuna vardıkları çalışmalarıdır.

\section{Veri Seti ve Model}

Çalışmada, yenilenebilir ve yenilenemeyen enerji tüketimi ile ekonomik büyüme ilişkisi, 1990-2013 dönemini kapsayan yıllık veriler kullanılarak 28 OECD ülkesi için test edilecektir. Çalışmada kullanılan tüm veriler Dünya Bankası veri tabanından (World Development Indicators) ve BP'nin 2014 dünya enerji istatistikleri raporundan (BP Statistical Review of World Energy 2014 Workbook) elde edilmiştir.

Tablo 1. Panel Veri Setindeki 28 OECD Ülkesi

\begin{tabular}{llll}
\hline 1 AVUSTURYA & 8 FINLANDIYA & 15 JAPONYA & 22 PORTEKIZ \\
2 AVUSTRALYA & 9 FRANSA & 16 GÜNEY KORE & 23 ISPANYA \\
3 BELÇIKA & 10 ALMANYA & 17 MEKSIKA & 24 ISVEÇ \\
4 KANADA & 11 YUNANISTAN & 18 HOLLANDA & 25 ISVIÇRE \\
5 ŞiLi & 12 IRLANDA & 19 YENI ZELANDA & 26 TÜRKIYE \\
6 ÇEK & 13 ISRAIL & 20 NORVEÇ & 27 BiRLEŞiK \\
CUMHURIYETi & 14 ITALYA & 21 POLONYA & KRALLIK \\
7 DANIMARKA & & 28 A.B.D. \\
\hline
\end{tabular}

Modelimizde serilerin logaritmik düzeyleri kullanılmış olup, değişkenlerimiz uygulamanın yapıldığı programdaki kodları ile verilmiştir. Çalışmada kullanılan tüm ekonometrik tahminler Eviews8 ve Stata13 paket programları ile yapılmıştır. Modelimiz aşağıdaki gibidir;

$G D P_{i t}=\alpha_{i t}+\beta_{1 i} R E N+\beta_{2 i} N R E N_{i t}+u_{i t}$

Enerji tüketimi; yenilenebilir (renewable: REN) ve yenilenemeyen (nonrenewable: NREN) enerji tüketimi olarak ayrı ayrı ele alınmıştır. Enerji tüketimi, eşdeğer milyon ton petrol cinsinden belirlenirken, büyümeyi temsilen reel GSYiH (GDP: Gross Domestic Produce, constant 2005 US\$) kullanılmıştır.

\section{Ekonometrik Yöntem}

Çalışmada dört aşamalı bir yöntemden hareket edilerek yenilenebilen ve yenilenemeyen enerji tüketimi ve ekonomik büyüme arasındaki ilişki panel veri analizi ile ortaya konulmaktadır. İlk aşamada serilerin durağanlık dereceleri Genişletilmiş Dickey Fuller-Fisher (ADF-Fisher) ve Im, Peseran, Shin birim kök testleri kullanılarak belirlenmektedir. İkinci aşamada değişken- 
ler arasında uzun dönemli bir ilişki olup olmadığı Pedroni ve Johansen Fisher Eş-bütünleşme testi ile araştırılmaktadır. Üçüncü aşamada değişkenler arasındaki nedensellik ilişkisi Granger testi ile ortaya konulmakta ve son aşamada uzun dönem parametre tahmininin yapılabilmesi için Pedroni $(2000,2001)$ tarafından geliştirilen Tam Değiştirilmiş En Küçük Kareler (Fully Modified Ordinary Least Squares (FMOLS)) testi uygulanmaktadır.

\subsection{Panel Birim Kök Testleri ve Sonuçları}

Panel veri analizinde birçok birim kök testi ADF testinin genişletilmesi temeline dayanmaktadır. Bu çalışmada ADF ve Im, Pesaran ve Shin (2003), birim kök testleri uygulanacaktır. ADF birim kök testi için geliştirilen model aşağıdadır;

$$
\Delta Y t=\beta_{0}+\beta_{1} t+\delta Y_{t-1}+\alpha i \sum_{i=1}^{n} \Delta Y_{t-i}+u_{t}
$$

Burada $\Delta$ birinci fark işlemcisini, t zaman trendini, $u_{t}$ arındırılmış hata terimini, $Y_{t}$ ise kullanılan serileri göstermekte, $n$ ise hata teriminin ardışık bağımlılığını gidermek için bilgi kriterleri tarafından belirlenen bağımlı değişkenin gecikme sayısıdır. Burada incelenen serinin durağan olmadığını gösteren sıfır hipotez $\delta=\mathbf{O}$ şeklinde kurulur. Özetle;

$H_{0}=p \geq 1$ veya $H_{0}=\delta \geq 0, H_{0}=\delta \geq 0$ seri durağan değildir.

$H_{1}=p<1$ veya $H_{1}=\delta<0 \quad$ seri durağandır.

Uygulanan test sonucunda serinin birim kök taşıdığı dolayısıyla durağan olmadığı bir durumda, aynı test serilerin birinci farkına ya da gerekirse daha yüksek derecelerdeki farkına uygulanarak seriler durağan hale getirilir.

Birim kök sınamasında kullandığımız diğer test Im, Pesaran ve Shin (IPS) birim kök testidir. IPS (2003), olabilirlik taslağını kullanarak eş zamanlı durağanlık ve durağan olmamayı göz önüne alan, panel için daha esnek ve hesaplama olarak daha kolay bir birim kök test süreci önermişlerdir (Barbieri, 2006). IPS testinde, panel veri analizinin sonuçlarını elde edebilmek için bireysel birim kök testleri birleştirilmiştir. Bu test dinamik heterojen panel veri analizi için geliştirilmiştir. Bu testte $\rho$ i yatay kesitler arasında (i'ler arasında) değişebilmekte ve her bir yatay kesit için ayrı ayrı birim kök olup olmadığını test edilmektedir. IPS testi paneldeki kesitler (örneğin ülkeler) arasında heterojenliğe izin vermektedir (Kök ve Şimşek: 2006).

Her bir yatay kesit için ayrı bir ADF belirlenerek IPS testine başlanmaktadır:

$$
\Delta Y_{i t}=\alpha Y_{i t-1}+\sum_{j=1}^{p i} \beta_{i j} \Delta Y_{i t-j}+X^{\prime}{ }_{i t} \delta+u_{i t}
$$

IPS yöntemi;

$H_{0}: \alpha_{i}=0$ (bütün i'lerde birim kök vardır) hipotezini,

$H_{0}: \alpha_{i}<0$ (en azından bir i için) hipotezine karşı test etmektedir.

Çalışmada birinci nesil birim kök testleri olarak belirtilen IPS ve Fisher-ADF birim kök testlerinin yanında durağanlık sınamalarının daha güçlü sonuçlar vermesi için ikinci nesil birim kök testi analize dahil edilmiştir.

Pesaran (2007) kesit açısından genişletilmiş Dickey-Fuller (Cross-Sectionally Augmented Dickey-Fuller) testi olarak adlandırılan panel birim kök testi geliştirmiştir. Test aşağıdaki modele dayanmaktadır: 
$Y_{i t}=\left(1-\phi_{i}\right) Y_{i, t-1}+u_{i t}, \quad t=1, \ldots ., T ; i=1, \ldots ., N$

Panelin geneline ait olan CIPS istatistiği ise $C I P S=\sum_{i=1}^{N} \frac{C A D F}{N}$ şeklinde hesaplanır.

Çalışmada serilerin durağanlık sınamasında CADF birim kök testinin panelin geneline ait sonuçlarını veren CIPS test istatistiği kullanılmıştır. Bu çerçevede panel birim kök testi bulguları düzeylerine göre; sabitli, trendli ve birinci farkı alınmış şekilde aşağıda Tablo 2'de verilmiştir.

Tablo 2. Panel Birim Kök Test Sonuçları

\begin{tabular}{lccc}
\hline & Sabitli & Sabitli Trend & $\Delta$ Sabitli \\
\hline Fisher-ADF & & t-istatistiği & \\
\hline \hline GDP & 56.46 & 41.00 & $243.91^{* * *}$ \\
REN & 62.79 & $123.78^{* * *}$ & $463.64^{* * *}$ \\
NREN & $98.57^{* * *}$ & 49.35 & $313.53^{* * *}$ \\
\hline IPS & & t-istatistiği & \\
\hline \hline GDP & 0.18 & 3.54 & $-11.86^{* * *}$ \\
REN & 2.66 & $-4.26^{* * *}$ & $-22.19^{* * *}$ \\
NREN & $-3.61^{* * *}$ & 4.89 & $-14.24^{* * *}$ \\
\hline CIPS & & t-istatistiği & \\
\hline \hline GDP & -1.823 & -2.675 & $-3.685^{* * *}$ \\
REN & -2.939 & $-3.434^{* *}$ & $-5.295^{* * *}$ \\
NREN & $-2.271^{*}$ & $-2.840^{* *}$ & $-4.909^{* * *}$ \\
\hline
\end{tabular}

$* * *, * *, *$, sırasıyla \%1, \%5 ve \%10 düzeyinde anlamlılığı, $\Delta:$ birinci farkı göstermektedir. Optimal gecikme uzunluğu Akaike bilgi kriterine göre belirlenmiştir. CIPS testi için kritik değerler Pesaran (2007)'den elde edilmiştir.

Panel değişkenlerin, t-istatistikleri ve olasılık sonuçlarına bakıldığında sabitli ve sabitli trend düzeyinde (NREN değişkeni dışında) birim kök problemi içerdiği görülmektedir. Bu nedenle serilerin birinci farkları araştırılmıştır. Panel değişkenler için serilerin birinci farklarından elde edilen bulgularda serilerin durağan hale geldikleri görülmektedir.

\subsection{Pedroni - Johansen Fisher Eş Bütünleşme Testi ve Sonuçları}

Çalışmada, birim kökün varlığı araştırıldıktan sonra seriler arsında uzun dönemli bir ilişkinin bulunup bulunmadığını ortaya çıkarmak için Pedroni ve Johansen Fisher panel eş bütünleşme testi kullanılmıştır.

Pedroni, 1997, 1999, 2000 ve 2004 yıllarında eş bütünleşme analizlerinde hetorejenliğe izin veren birkaç test önerisi ileri sürmüştür (Asteriou ve Hall, 2007: 373). Bu test, eş bütünleşme vektöründeki heterojenliğe izin veren bir test olup, yalnızca dinamik ve sabit etkilerin panelin kesitleri arasında farklı olmasına da izin vermektedir. Bunu yanında alternatif hipotez altında eş bütünleşik vektörün kesitler arasında farklı olmasına da izin veren bu test, literatürde en fazla kullanılan eş bütünleşme testlerinden biridir (Kök ve Şimşek: 2006). Pedroni'nin önerdiği tüm testler aşağıdaki gibi bir denklemden elde edilen artıklar üzerine kurulmuştur. Bu nedenle ilk aşama, eş bütünleşme regresyonundan elde edilen artıkları hesaplamaktır (Pedroni, 1999; 656):

$$
Y_{i, t}=\alpha_{i}+\delta_{i} t+\beta_{1 i} x_{2 i, t}+\ldots+\beta_{M i, t}+u_{i, t}, t=1, \ldots, T ; i=1, \ldots, N ; m=1, \ldots, M
$$


Burada T zaman periyodundaki gözlem sayısı, N paneldeki yatay kesitlerin toplam sayısı ve $\mathrm{M}$ regresyondaki değişkenlerin sayısıdır. $\mathrm{N}$ tane farklı kesit olması nedeniyle, her biri $\mathrm{M}$ tane değişken içeren $N$ tane farklı denklem olacaktır. $\beta_{1 i}, \beta 2 i, \ldots, \beta M i$, eğim katsayıları paneldeki yatay kesitler arası değişebilmektedir. $\alpha_{i}$ parametresi paneldeki kesitlere özgü sabit ya da bireysel kesitler arasında farklı olabilen sabit etki parametresidir. Pedroni, eş bütünleşme olmadığı boş hipotezine karşı yedi adet farklı test önermiştir. Bunların dördü panel eş bütünleşme istatistiği, diğer üçü grup ortalamasının panel eş bütünleşme istatistikleridir. Birinci kategori içindeki dört testten ilki, parametrik olmayan varyans oranı tipinde bir istatistiktir. İkincisi Phillips-Peron (PP) rho istatistiğine benzer parametrik olmayan istatistiğin panel versiyonudur. Bu kategorideki üçüncü istatistik de parametrik değildir ve PP $t$ istatistiğine benzemektedir. Dördüncü istatistik ise Augmented Dickey Fuller (ADF) t istatistiğine benzer parametrik bir istatistiktir. İkinci kategoride üç testten ilki PP rho istatistiğine benzemekte iken, diğer ikisi sırasıyla PP t ve ADF t istatistiklerine benzemektedir (Kök ve Şimşek, 2006).

Maddala ve Wu (1999) tarafından geliştirilen Johanser-Fisher panel eş bütünleşme testi klasik Johansen ve Juselius eş bütünleşme testinin panel verilere uygulanmasıdır. Bu testin istatistikleri her bir ülkeye teker teker uygulanan klasik Johansen (1998) eş bütünleşme testinin trace ve/veya maksimum istatistiklerinin olasılık değerlerinin toplulaştırılması ile elde edilmektedir. Bu kapsamda Johansen (1988) eş bütünleşme testinin olasılık değeri olmak üzere Johansen-Fisher için panel eş bütünleşme test istatistiği aşağıdaki denklemde gösterildiği gibi hesaplanmaktadır;

$-2 \sum_{i=1}^{N} \log \left(\pi_{i}\right) \rightarrow \chi_{2 N}^{2}$

Burada, $\chi^{2}$ değeri, Johansen (1988) eş bütünleşme testindeki Mackinnon vd. (1999) olasılık değerlerine bağlı olarak hesaplanan $\chi^{2}$ değerini göstermektedir. Testlerin Ho hipotezi "eş bütünleşme yoktur" şeklindedir. Çalışmamızdaki eş bütünleşme bulguları Tablo 3'de verilmiştir.

Tablo 3. Panel Eşbütünleşme Test Sonuçları

\begin{tabular}{lcc}
\hline Pedroni & & \\
\hline & & Within-Dimension \\
\hline Panel v-istatistiği & $13.55^{* * *}$ & $6,69 * * *$ \\
Panel rho- istatistiği & 0.82 & 1,31 \\
Panel PP- istatistiği & $-2.87^{* * *}$ & $-1.85^{* *}$ \\
Panel ADF- istatistiği & $-3.04^{* * *}$ & $-2.65^{* * *}$ \\
\hline & & Between Dimension \\
\hline Group rho- istatistiği & 2.44 & \\
Group PP- istatistiği & $-2.72 * * *$ & \\
Group ADF- istatistiği & $-3.91^{* * *}$ & \\
\hline Johansen Fisher & & Max-eigen Test \\
\hline \hline
\end{tabular}


Pedroni eşbütünleşme testi sonuçlarına göre, Ho hipotezi (seriler arasında eş bütünleşme yoktur) reddedilmiştir. Genel olarak değerlendirildiğinde Pedroni eşbütünleşme testindeki hem panel hem de grup istatistiklerini oluşturan yedi testten beşi seriler arasında kuvvetli bir eşbütünleşme ilişkisini vermektedir. Johansen Fisher eşbütünleşme testi sonuçlarından da Ho hipotezi test istatistikleri anlamlı olduğu için reddedilmiş dolayısıyla uzun dönemde yenilenebilir enerji ve yenilenemeyen enerji tüketimi ile ekonomik büyüme değişkenleri arasında eşbütünleşme olduğu sonucuna ulaşılmıştır.

\subsection{Granger Nedensellik Testi ve Sonuçları}

Granger nedensellik testi, aralarında bir ilişki olup olmadığı sorgulanan değişkenler arasındaki ilişkinin varlığını ortaya koyma ve bir ilişki varsa bu ilişkinin yönünü belirlemeye yarayan istatistiksel bir testtir. Bu test, iki değişkenden $X^{\prime}$ in geçmiş değerleri $Y^{\prime}$ nin öngörüsü hakkında açıklayıcı bir bilgi veriyorsa, $X$ değişkeni, $Y$ değişkeninin Granger nedenidir şeklinde açıklanmaktadır (Granger,1969). Granger nedenselliği aşağıdaki eşitlikler yardımıyla test edilmektedir.

$$
\begin{aligned}
& Y_{t}=\sum_{i=1}^{m} \alpha_{i} Y_{t-i}+\sum_{i=1}^{m} \beta_{i} X_{t-i}+u_{1 t} \\
& X_{t}=\sum_{i=1}^{m} \theta_{i} X_{t-i}+\sum_{i=1}^{m} \gamma_{i} Y_{t-i}+u_{2 t}
\end{aligned}
$$

Burada $\alpha, \beta, \theta$ ve $\gamma$ gecikme katsayılarını, bütün sayılar için ortak gecikme derecesini ve hata terimlerinin birbirinden bağımsız oldukları varsayılmaktadır. Granger nedensellik testi, eşitlik (8) ve (9) numaralı denklemde verilen gecikme katsayılarının sıfıra eşitliğinin anlamlılığının test edilmesi ile yapılır. Hipotez çift yönlü kurularak, nedenselliğin yönünün tek yönlü mü yoksa çift yönlü mü olduğu belirlenir. Çalışmamızda, değişkenler arasında uzun dönemli eş bütünleşme ilişkisi tespit edildiğinden Granger nedensellik testi uygulanmış ve sonuçlar Tablo 4'de verilmiştir.

\begin{tabular}{|c|c|c|}
\hline Değişkenler & F-i̇statistiği & Olasılık \\
\hline NREN $\leftarrow \rightarrow$ GDP & $\begin{array}{l}687.55 \\
202.40\end{array}$ & $\begin{array}{c}0.0011 * * * \\
3 . E-09 * * *\end{array}$ \\
\hline REN - . - GDP & 169.99 & 0.1836 \\
\hline GDP $\rightarrow$ REN & 876.96 & $0.0002^{* * *}$ \\
\hline
\end{tabular}

Tablo 4. Granger Nedensellik Testi Sonuçları

***, \%1 düzeyinde anlamlılığı göstermektedir. Gecikme uzunluğu iki olarak belirlenmiştir. Ho: Granger nedeni değildir; H1: Granger nedenidir. NREN $\leftarrow \rightarrow G D P$; nedensellik yönünün enerji tüketimi ve büyüme arasında çift yönlü olduğunu, GDP $\rightarrow$ REN; nedensellik yönünün ekonomik büyümeden enerji tüketimine doğru olduğunu, REN----GDP; nedensellik yönünün iki değişken arasında olmadığını yani birbirinden etkilenmediğini ifade etmektedir.

Granger nedensellik analizine göre \%1 anlamlılık düzeyinde değişkenler arasında Ho hipotezi, sadece yenilenebilir enerjiden GDP'ye doğru bir harekette kabul edilmiştir. Başka bir deyişle yenilenebilir enerjiden GDP'ye doğru bir nedenselliğin olmadığı görülürken, bu durum yenilenebilir enerji tüketimindeki bir artışın GDP üzerinde önemli bir değişikliğe yol açmadığı sonucunu verir. GDP'den yenilenebilir enerjiye doğru ise tek yönlü bir nedensellik ilişkisi ortaya çıkmıştır. Bunun dışında yenilenemeyen enerji tüketimi ile GSYiH arasında çift yönlü bir nedensellik ilişkisi tespit edilmiştir. 


\subsection{Eş Bütünleşme Katsayı Tahmin Yöntemi ve Sonuçları}

Çalışmada, panel eş bütünleşme testleri uygulandıktan sonra, değişkenlerimizin kat sayılarını da beklentilerimize göre test etmek için, Pedroni $(2000,2001)$ tarafından geliştirilen FMOLS ve DOLS olmak üzere iki farklı yöntem kullanılmıştır.

FMOLS yöntemi, standart sabit etkili tahmincilerdeki (otokorelasyon, değişen varyans gibi sorunlardan kaynaklanan) sapmaları düzeltirken, DOLS yöntemi modele dinamik unsurları da dahil ederek statik regresyondaki (özellikle içsellik sorunlarından kaynaklanan) sapmaları da giderebilecek özelliğe sahip bir yöntemdir (Kök ve diğ., 2010: 8). Pedroni'nin bireysel kesitler arasında önemli ölçüde heterojenliğe izin veren bu FMOLS yöntemi, sabit terimin, hata terimi ve bağımsız değiş̧kenlerin farkları arasındaki olası korelasyonun varlığını hesaba katmaktadır (Kök ve Şimşek, 2006: 7-8).

Pedroni (2000) tarafından geliştirilen grup ortalama panel FMOLS yöntemi aşağıdaki panel regresyon modeline dayanmaktadır (aktaran; Nazlıŏlu, 2010: 98);

$$
y_{i t}=\alpha_{i}+\beta x_{i t}+\mu_{i t} \quad \text { ve } \quad x_{i t}=x_{i t-1}+e_{i t}
$$

Bu denklemde y bağımlı değişkeni, $\mathrm{x}$ bağımsız değişkenleri ve $\alpha$ sabit etkileri gösterirken, paneli oluşturan kesitler arasında ise bağımlılığın olmadığı varsayılmaktadır. Eşitlik (10)'da hata terimleri durağan bir süreç olması nedeniyle, y birinci dereceden bütünleşikse, $\mathrm{y}$ ve $\mathrm{x}$ arasında uzun dönem eş bütünleşme ilişkisi söz konusudur. Böylece, $\beta$ tahmin edilmesi gereken uzun dönem eş bütünleşme vektörünü göstermektedir (Nazlıoğlu, 2010: 98-99).

Tablo 5. FMOLS Test Sonuçları

\begin{tabular}{|c|c|c|}
\hline \multicolumn{3}{|c|}{ FMOLS } \\
\hline Değişkenler & Katsayı & t-istatistiği \\
\hline NREN & $0.800027^{* * *}$ & 8.93 \\
\hline REN & $0.445296 * * *$ & 13.13 \\
\hline
\end{tabular}

*** yüzde 1 düzeyinde anlamlılığı göstermektedir.

Panel FMOLS test sonuçları panel bazında değerlendirildiğinde GSYiH'nin işareti beklenildiği gibi pozitif ve istatistiksel olarak \%1 düzeyinde anlamlıdır. Yani uzun dönemde yenilenebilen ve yenilenemeyen enerji tüketimindeki bir artış, ekonomik büyümeyi panel genelinde pozitif bir şekilde etkilemekte ve yenilenebilir enerjinin uzun dönemde, fosil yakıtların büyümeye olan pozitif etkisini yakalayabileceğini göstermiştir. Panel genelinde yenilenebilir enerji tüketimi katsayısı 0,44 olarak hesaplanmıştır. Yani 28 OECD ülkesinde yenilenebilir enerji tüketimindeki \%10'luk bir artış, GSYiH üzerinde uzun dönemde yaklaşık olarak \%4.4'lük bir büyüme sağlayacaktır. Yenilenemeyen enerji tüketiminde \%10'luk bir artış ise uzun dönemde GSYiH'yi \%8.0 artıracaktır. Dolayısıyla NREN değişken katsayısı beklentilerimize uygun çıkmıştır. REN katsayısı ise Granger nedensellik testi sonuçlarından farklı olarak yenilenebilir enerjinin uzun dönemde iktisadi büyümeyi olumlu etkilediğini göstermiştir.

\section{Sonuç, Değerlendirme ve Öneriler}

Gelişen teknolojiyle fosil ve nükleer enerji kullanımındaki artış beraberinde çeşitli çevre sorunlarını da ortaya çıkarmıştır. Bunların başında küresel ısınma, iklim değişikliği, atmosfer kirliliği ve sera etkisi gibi dünyayı meşgul eden sorunlar yer almaktadır. Bütün bu sorunlara karşın son yıllarda dünyada artan çevre bilincinin etkisiyle, daha temiz, sürdürülebilir bir çevre anlayışı hakim olmaya başlamış ve çevresel sorunların çözümü için ülkelerin yenilenebilir ener- 
ji politikalarında önemli derecede değişmeler meydana gelmiştir. Temiz ve zararsız olmasının yanında yerli kaynaklar oldukları için enerjide dışa bağımlılığın azalmasına ve istihdamın artmasına katkıda bulunan yenilenebilir enerji kaynakları, iktisadi büyüme için önemli unsurlardan biri olmaya başlamıştır.

Çalışmada, değişkenler arasında uzun dönemli bir ilişkinin olup olmadığını belirlemek için Johansen-Fisher ve Pedroni eş bütünleşme testleri uygulanmıştır. Elde edilen bulgular değişkenler arasında eş bütünleşmenin olduğunu göstermiştir. Daha sonra ortaya çıkan bu ilişkinin yönü Granger nedensellik testi ile belirlenmiştir. Değişkenler arasındaki ilişkinin yönleri; NREN $\leftarrow \rightarrow$ GDP, GDP $\rightarrow$ REN, REN - - - GDP şeklinde tespit edilmiştir.

Bu sonuçlar doğrultusunda değişkenlerin uzun dönem eşbütünleşme kat sayılarını test etmek için Pedroni FMOLS yöntemi kullanılmış ve elde edilen bulgular panel genelinde yenilenebilir enerjinin büyümeyi önemli oranda pozitif etkilediğini göstermiştir. Çalışmada elde edilen nedensellik yönleri, Payne (2011), Apergis and Payne (2011), Magnani and Vaona (2013), Apergis and Danuletiu (2014) gibi yazarların çalışmalarının sonuçları ile benzerlik göstermektedir.

Çalışmanın sonucu, yenilenemeyen enerji kaynakları kullanımının devam etmesi halinde bazı OECD ülkelerinin iktisadi büyümelerinin olumsuz etkilenebileceğini, yenilenebilir enerji kullanımındaki artışın söz konusu ülkelerin iktisadi büyümesine katkı sağlayacağını, hatta bu sayede ülkelerin uzun dönemde fosil yakıt bağımlıı̆̆ından kurtulabileceğini göstermiştir.

Dünyada, fosil yakıt ve nükleer güç kullanımıyla üretilen enerji tüketiminin yarattığı sorunlar; doğal çevreye daha az zarar veren, daha verimli teknolojilere doğru yönelimi zorunlu kılmaktadır. Ekonomik büyümeden ödün vermeden tasarruf ve verimli teknolojilerle, enerji tüketimini azaltmak en iyi politika önerisi olarak görülmektedir. 


\section{Kaynaklar}

ACARAVCI, A. and i. ÖZTÜRK, (2010), "On the relationship between energy consumption, CO2 emissions and economic growth in Europe. Energy", 35(12): 5412-5420.

APERGIS, N. and J. E. PAYNE (2009a), "Energy consumption and economic growth in Central America: evidence from a panel cointegration and error correction model", Energy Economics, No: 31, pp. 211-216.

APERGIS, N. and J. E. PAYNE (2009b), "CO2 emissions, energy usage, and output in Central America”, Energy Policy, Vol. 37, No:8, pp. 3282-3286.

APERGIS, N. and J. E. PAYNE (2011), "The renewable energy consumption-growth nexus in Central America", Applied Energy, Vol. 88, No: 1, pp. 343-347.

APERGIS, N. and D.C. DANULETIU (2014), "Renewable energy and economic growth: evidence from the sign of panel long-run causality", International Journal of Energy Economics and Policy, Vol.4, No: 4, pp. 578-587.

ASTERIOU, D. and S. G. HALL, (2007), Applied econometrics: A modern approach using eviews and microfit revised edition, Palgrave Macmillan, New York.

NAZLıOĞLU, Ş. (2010), “Makro İktisat Politikalarının Tarım Sektörü Üzerindeki Etkileri: Gelişmiş ve Gelişmekte Olan Ülkeler İçin Bir Karşılaştırma", Yayınlanmamış Doktora Tezi, T.C. Erciyes Üniversitesi Sosyal Bilimler Enstitüsü, Kayseri.

GHALI, K. H. and EL-SAKKA, M.I.T. (2004), "Energy Use and Output Growth in Canada: A Multivariate Cointegration Analysis", Energy Economics, 24, 355- 365.

GRANGER, C.W.J. (1969), "Investigating causal relations by econometric models and cross-spectral methods", Econometrica: Journal of the Econometric Society, Vol. 37, No: 3, pp. 424-438.

HAMILTON, J. D. (1983), "Oil and the Macroeconomy Since World War II", Journal of Political Economy, 91, 228-248.

IM, K. S., M. H. PESARAN and Y. SHIN (2003), "Testing for Unit Roots in Heterogeneous Panels", Journal Of Econometrics, No: 115, pp. 53-74.

JOHANSEN, S. (1988), "Statistical analysis of cointegration vectors. Journal of Economic Dynamics and Control", vol. 12, No. 2/3, pp. 231-254.

KÖK, R. ve N. ŞiMŞEK (2006), “Endüstri-içi Dış Ticaret, Patentler ve Uluslararası Teknolojik Yayılma”, UEK-TEK 2006 Uluslararası Ekonomi Konferansı, Türkiye Ekonomi Kurumu, 11-13 Eylül, Ankara.

KÖK, R., M. S. ISPIR ve A. A. ARI (2010), "Zengin Ülkelerden Azgelişmiş Ülkelere Kaynak Aktarma Mekanizmasının Gerekliliği ve Evrensel Bölüşüm Parametresi Üzerine Bir Deneme", http://kisi.deu.edu.tr/ recep.kok/Zengin_ispir.pdf, (10.04.2015).

KRAFT, J. ve A. KRAFT (1978), "Relationship Between Energy and GNP”, Journal of Energy and Development, No:3, pp. 401- 403.

LEE, C.C (2006) "The causality relationship between energy consumption and GDP in G-11 countries revisite", Energy Policy, No:34, pp. 1086-1093.

LEE, C. C. and C. P. CHANG (2008), "Energy consumption and economic growth in Asian economies: a more comprehensive analysis using panel data", Resource and Energy Economics, Vol. 30, No:1, pp. 50-65.

MACKINNON, J. G., HAUG A. A. ve MICHELIS, L. (1999), "Numerical distribution functions of likelihood ratio tests for cointegration", Journal of Applied Econometrics, (14), 563-577

MADDALA, G. S. and S., WU (1999), "A comparative study of unit root tests with panel data and a new simle test", Oxford Bulletion of Economics and Statictics, No: 61, pp. 631-652.

MAGNANI, N. and A. VAONA (2013), "Regional spillover effects of renewable energy generation in Italy", Energy Policy, No: 56, pp. 663-671.

MEHRARA, M. (2007) "Energy consumption and economic growth: the case of oil exporting countries", Energy Policy, Vol. 35, No:5, pp. 2939-2945.

NARAYAN, P. K. and R. SMYT (2008), "Energy consumption and real GDP in G7 countries: new evidence from panel cointegration with structural breaks", Energy Economics, No: 30, pp. 2331-2341.

PAYNE, J. E. (2011), “On biomass energy consumption and real output in the US", Energy Sources, Part B: Economics, Planning, and Policy, Vol. 6, No: 1, pp. 47-52.

PEDRONI, P. (1999), "Critical Values for Cointegration Tests in Heterogeneous Panels with Multiple Regressors", Oxford Bulletin of Economics and Statistics, Vol. 61, No: 4, pp. 653-670. 
Eskişehir Osmangazi Üniversitesi IiBF Dergisi

PEDRONI, P. (2000), "Fully-Modified OLS for Heterogeneous Cointegrated Panels", Advances in Econometrics, No: 15, pp. 93-130.

PEDRONI, P. (2001), "Purchasingpowerparitytests in cointegratedpanels", Review of Economics and Statistics, No: 83, pp. 727-731.

PESARAN, M.H. (2007), "A Simple Panel Unit Root Test in the Presence of Cross-Section Dependence", Journal of Applied Econometrics, 22, 265-312.

ROMANO, A. A. and G. SCANDURRA, (2013), "Energy Consumption-Gross Domestic Product Causal Relationship in the Italian Regions", Classification and Data Mining, Springer Berlin Heidelberg, 279-286.

STERN, D. I. and C. J. CLEVELAND (2004), "Energy and Economic Growth", Rensselear Working Papers in Economics, No: 0410, pp. 1-41.

WOLDE-RUFAEL, Y. (2005) "Energy demand and economic growth: the African experience", Journal of Policy Modeling, Vol. 27, No: 8, pp. 891-903.

http://www.worldbank.org/, (01.02.2015).

http://www.bp.com/en/global/corporate/about-bp/energy-economics/statistical-review-of-world-energy.html, (05.05.2015). 